\title{
A Proteomic-Based Approach to Study the Mechanism of Cytotoxicity Induced by Interleukin-1 $\alpha$ and Cycloheximide
}

\author{
Katarzyna Macur ${ }^{1}$ Jolanta Grzenkowicz-Wydra ${ }^{2}$ Lucyna Konieczna ${ }^{3}$. \\ Jacek Bigda $^{4} \cdot$ Caterina Temporini $^{5} \cdot$ Sara Tengattini $^{5} \cdot$ Tomasz Bączek $^{3}$ (])
}

Received: 24 March 2017 / Revised: 18 July 2017 / Accepted: 10 August 2017 / Published online: 30 August 2017

(C) The Author(s) 2017. This article is an open access publication

\begin{abstract}
The exposure of HeLa cells to interleukin-1 alpha (IL-1 $\alpha$ ) in the presence of cycloheximide (CHX) leads to the release of active tumor necrosis factor alpha (TNF- $\alpha$ ), eliciting cytocidal effect on these cells. A mass spectrometry (MS)-based analysis of the qualitative proteomic profiles of the HeLa cells treated only with IL- $1 \alpha$, CHX or simultaneously with IL- $1 \alpha$ and CHX, in comparison to an untreated control, enabled to distinguish protein candidates possibly involved in this process. Among them protein disulphide isomerase (PDI) seemed to be particularly interesting for further research. Therefore, we focused on quantitative changes of PDI levels in HeLa cells subjected to IL-1 $\alpha$ and
\end{abstract}

Published in the topical collection Peptide and Protein Analysis with Debby Mangelings and Gerhard K. E. Scriba as editors.

Electronic supplementary material The online version of this article (doi:10.1007/s10337-017-3382-3) contains supplementary material, which is available to authorized users.

Tomasz Bączek

tbaczek@gumed.edu.pl

1 Intercollegiate Faculty of Biotechnology UG and MUG, University of Gdańsk, ul. Abrahama 58, 80-307 Gdańsk, Poland

2 Laboratory of Pomeranian Science and Technology Park, al. Zwycięstwa 96/98, 81-451 Gdynia, Poland

3 Department of Pharmaceutical Chemistry, Medical University of Gdańsk, al. Hallera 107, 80-416 Gdańsk, Poland

4 Cell Biology Unit, Department of Medical Biotechnology, Intercollegiate Faculty of Biotechnology UG and MUG, Medical University of Gdańsk, ul. Dębinki 1, 80-210 Gdańsk, Poland

5 Department of Drug Sciences, University of Pavia, Via Taramelli 12, 27100 Pavia, Italy
CHX. Enzyme-linked immunosorbent assay (ELISA) was employed for determination of PDI concentrations in the investigated, differently treated HeLa cells. The obtained results confirmed up-regulation of PDI only in the cells stimulated with IL-1 $\alpha$ alone. In contrary, the PDI levels in HeLa cells exposed to both IL-1 $\alpha$ and CHX, where apoptotic process was intensive, did not increase significantly. Finally, we discuss how different expression levels of PDI together with other proteins, which were detected in this study, may influence the induction of cytotoxic effect and modulate sensitivity to cytotoxic action of IL1.

Keywords HPLC-MS/MS · Protein disulphide isomerase (PDI) - Interleukin-1 $\alpha(\mathrm{IL}-1 \alpha) \cdot$ Cycloheximide $~$ Cytotoxicity $\cdot$ HeLa proteome

\section{Introduction}

Tumor necrosis factor alpha (TNF- $\alpha)$ and interleukin-1 alpha (IL- $1 \alpha)$ are proinflammatory cytokines. TNF- $\alpha$ induces cytotoxicity in both, tumor and healthy cells. IL-1 can also trigger cytostatic or cytotoxic effect, but usually in the conditions of simultaneous treatment with metabolic inhibitors. Nevertheless, in contrast to apoptosis caused by TNF- $\alpha$, which is a potent cytotoxic agent, the IL- 1 activity leading to cell death is not completely understood [1, 2]. In the presence of protein synthesis inhibitor-cycloheximide (CHX), cytotoxicity was also observed in human cervical carcinoma cell line (HeLa) in response to IL-1 $\alpha$. There, it was dependent on the increased release of soluble and presence of transmembrane TNF- $\alpha$. However, the proteins involved in this mechanism remain unknown. Interestingly, this cytocidal effect was not detected after selective IL- $1 \alpha$ 
stimulation, or the effect was lower when the cells were only treated with CHX [3].

Mass spectrometry (MS)-based proteomics is a powerful approach for investigating the global changes in protein patterns characteristic for the cell, tissue or organism in certain conditions [4]. In the present research we chose to determine potential protein candidates participating in evocation of the cytocidal effect observed in HeLa cells after IL- $1 \alpha$ and CHX treatment. We used high-performance liquid chromatography coupled with tandem mass spectrometry (HPLC-MS/ MS) [5], to detect possible differences in proteomic profiles between HeLa cells in response of IL- $1 \alpha / \mathrm{CHX}$, IL- $1 \alpha$ and CHX. This allowed us to select proteins, which were detected only in one of the four analyzed proteomes. Among them, the protein disulphide isomerase (PDI) was found only in HeLa cells subjected to the IL-1 $\alpha$. The up-regulation of the PDI gene (P4HB) expression was shown to decrease the TNF- $\alpha$ gene and protein expression [6]. The PDI causes also conformational changes of the TNF- $\alpha$ converting enzymea disintegrin and metalloproteinase-17 (ADAM17). This leads to downregulation of ADAM17 enzymatic activity and prevention of pro-TNF- $\alpha$ processing to the secreted form [7, 8]. Therefore, PDI seemed to be particularly interesting for further examination.

In our study, we focused on quantitative changes in PDI concentrations in the investigated samples. The protein levels were measured by ELISA test in the HeLa cells exposed to both, IL- $\alpha$ and CHX, where the cytocidal effect was remarkable. These results were also compared to the detected PDI concentrations in an untreated control sample and in the HeLa cells stimulated alone with IL-1 $\alpha$, in which cytotoxicity was not observed, or treated with CHX, where it was much less pronounced [3]. This enabled comprehensive analysis of the PDI in view of its possible contribution to the TNF- $\alpha$ release, induced by interleukin- $1 \alpha$ (IL- $1 \alpha)$ and cycloheximide (CHX), which was shown to elicit the cytocidal activity on HeLa cells. Finally, the potential role in this process of other distinguished in the presented research proteins was also discussed.

\section{Materials and Methods}

\section{HeLa Samples Preparation}

\section{HeLa Cell Culture and Induction of Cytotoxic Effect}

HeLa cells $\left(2 \times 10^{6}\right)$ were seeded in four $6 \mathrm{~cm}$ plates in $1 \mathrm{~mL}$ growth medium per well. They were cultured in humidified atmosphere $\left(5 \% \mathrm{CO}_{2}\right)$, at $37^{\circ} \mathrm{C}$, in Dulbecco's modified Eagle's medium (Sigma-Aldrich, Steinheim, Germany), which was supplemented with $100 \mathrm{U} \mathrm{mL}^{-1}$ penicillin, $100 \mu \mathrm{g} \mathrm{mL}^{-1}$ streptomycin, $2 \mathrm{mM}$ L-glutamine
(Sigma-Aldrich, Steinheim, Germany) and 10\% fetal calf serum (Sigma-Aldrich, St. Louis, MO, USA). They were used after $24 \mathrm{~h}$ at $90 \%$ confluence. Afterwards the cells were incubated:

1. alone as a control- $\mathrm{HeLaK}$

or after exposure to:

2. $100 \mathrm{U} \mathrm{mL}^{-1}$ recombinant human interleukin-1 alpha (IL-1 $\alpha$ ). The IL- $1 \alpha$, which possessed a specific activity $3.3 \times 10^{7} \mathrm{U} \mathrm{mg}^{-1}$ protein and purity $>98 \%$, was purchased at eBioscience (Vienna, Austria)—HeLaIL-1,

3. $25 \mu \mathrm{g} \mathrm{mL}^{-1}$ cycloheximide (CHX). The CHX was obtained from Sigma-Aldrich (St. Louis, MO, USA) HeLaCHX,

4. both $100 \mathrm{U} \mathrm{mL}^{-1} \mathrm{IL}-1 \alpha$ and $25 \mu \mathrm{g} \mathrm{mL}^{-1} \mathrm{CHX}-$ HeLaIL-1/CHX.

After $14 \mathrm{~h}$ stimulation the supernatants (media) were discarded. Furthermore, the harvested cells were precipitated and the samples were lysed.

The viability of HeLa cells: after exposure to IL- $1 \alpha$, CHX, IL- $1 \alpha / \mathrm{CHX}$ and untreated HeLa control, was measured by neutral red uptake method [9] using In Vitro Toxicology Assay Kit Neutral Red Based (Sigma-Aldrich, St. Louis, MO, USA) on Multiskan FC Microplate Photometer (Thermo Scientific, Rockford, IL, USA), according to the manufacturer's instructions.

The details of the HeLa cell culture and cytotoxicity assay are given elsewhere [3].

\section{HeLa Cell Lysates Preparation}

The plates with HeLa cells were placed on ice. The cells were washed $1 \times$ in PBS (prepared from Phosphate Buffered Saline Dulbecco A tablets purchased at Oxoid, Basingstoke, UK) and carefully harvested from the plate with rubber policeman in $1 \mathrm{~mL}$ of PBS. Next, they were placed in Eppendorf test tubes, centrifuged $(1000 \times g)$ and supernatants discarded. The cell precipitates were lysed in $110 \mu \mathrm{L}$ of $20 \mathrm{mM}$ Tris- $\mathrm{HCl}$ lysis buffer ( $\mathrm{pH} 7.5$ ), which contained $150 \mathrm{mM} \mathrm{NaCl}, 1 \mathrm{mM}$ EDTA and 1\% Triton X-100 (all substances were purchased from Sigma-Aldrich, St. Louis, MO, USA). The lysates were frozen in $-80^{\circ} \mathrm{C}$ and sonicated after de-freezing to obtain total lysis. Then the samples were centrifuged $\left(14,000 \times g\right.$, at $4{ }^{\circ} \mathrm{C}$, for $\left.20 \mathrm{~min}\right)$, supernatants collected to new Eppendorf test tubes, and stored in $-80{ }^{\circ} \mathrm{C}$ prior to their analysis. The obtained protein concentrations were measured using commercially available Qubit Protein Assay Kit on Qubit 2.0 Fluorometer (Invitrogen, Calsbad, CA, USA), according to the protocol provided by the producer. 


\section{Protein Digests Preparation}

$40 \mu \mathrm{L}$ of HeLaK, HeLaIL- $1 \alpha$, HeLaCHX and HeLaIL- $1 \alpha /$ CHX lysates $\left(0.2 \mathrm{mg} \mathrm{mL}^{-1}\right)$ were submitted to the protein digestion. At first, $20 \mu \mathrm{L}$ of $100 \mathrm{mM}$ DTT (dithiotreitol), freshly prepared in $100 \mathrm{mM} \mathrm{NH}_{4} \mathrm{HCO}_{3}$ buffer ( $\mathrm{pH}$ 8.5), was added to each HeLa lysate sample. Afterwards, the samples were incubated in $60{ }^{\circ} \mathrm{C}$ for $30 \mathrm{~min}$ to allow reduction of disulphide bridges. After cooling down to $20{ }^{\circ} \mathrm{C}$, trypsin (100 $\mu \mathrm{g} \mathrm{mL}^{-1}$; enzyme:substrate ratio 1:50) was added to each sample. The digestion process was performed overnight $(12 \mathrm{~h})$ at $37^{\circ} \mathrm{C}$. The proteolysis was then quenched by acidification with formic acid (FA). The obtained tryptic digests concentrations were $0.1 \mu \mathrm{g} \mu \mathrm{L}^{-1}$. They were then analyzed by HPLC-MS/MS on the same day.

Water used in the experiments was obtained by passing through the Direct-Q water purification system (Millipore, Bedford, MA, USA). The DTT, $\mathrm{NH}_{4} \mathrm{HCO}_{3}$ and FA used in these experiments were purchased at Sigma-Aldrich (Steinheim, Germany).

\section{HPLC-MS/MS Analysis Conditions}

The HPLC-MS/MS experiments were performed on the Finnigan LTQ (Thermo Finnigan, San Jose, CA, USA) instrument. The HPLC was equipped with a thermostated column oven and Surveyor autosampler controlled at $10^{\circ} \mathrm{C}$, a quaternary gradient Surveyor MS pump and a diode array detection (DAD) system. It was combined on-line with the LTQ linear ion trap MS system with electrospray (ESI) ion source controlled by Xcalibur software 1.4 (Thermo Finnigan, San Jose, CA, USA).

The HPLC separation was performed on C-18 analytical column: XTerra MS C18 $3.5 \mu \mathrm{m}(2.1 \times 100 \mathrm{~mm})$ produced by Waters (Milford, MA, USA). Peptides elution was achieved using 120-min linear gradient from 0\% B to $60 \%$ of solvent $\mathrm{B}$ at $200 \mu \mathrm{L} \mathrm{m^{-1 }}$ flow rate. The mobile phases were: solvent $\mathrm{A}-0.1 \% \mathrm{FA}$ in water, and solvent $\mathrm{B}-0.1 \%$ FA in acetonitrile, mixed on-line. All HPLC reagents were MS-grade and obtained from Sigma-Aldrich (Steinheim, Germany). The injection volume was $10 \mu \mathrm{L}$.

The mass spectra were generated in positive ion mode, in the 500-2000 $\mathrm{m} / \mathrm{z}$ range, under constant instrumental conditions: source voltage $4.6 \mathrm{kV}$, capillary voltage $41 \mathrm{~V}$, sheath gas flow rate 40 (arbitrary units), auxiliary gas flow 10 (arbitrary units), sweep gas flow 1 (arbitrary units), capillary temperature $220^{\circ} \mathrm{C}$, and tube lens voltage $-105 \mathrm{~V}$. MS/ MS spectra were obtained by collision-induced dissociation in the linear ion trap, with an isolation width of $3 \mathrm{Da}(\mathrm{m} / \mathrm{z})$; the activation amplitude was $35 \%$ of ejection RF amplitude (this corresponds to $1.58 \mathrm{~V}$ ).

$\mathrm{m} / \mathrm{z}$ values, measured for the most intense peaks in acquired MS/MS spectra, were automatically searched against the protein database using the Sequest algorithm, incorporated into BioWorks 3.1 (Thermo Finnigan, San Jose, CA, USA). The human '.fasta' format was downloaded from UniProtKB [10]. Trypsin was defined as the cleavage enzyme and up to three missed cleavages were allowed. As a result of this search we obtained peptides scoring parameters - the difference between normalized cross-correlation functions for the first and second ranked results $\left(\Delta C_{n}\right)$ and cross-correlation score between the observed peptide fragment mass spectrum and the theoretically predicted one $\left(X_{\text {corr }}\right)$. To correctly identify peptides, we applied the levels of these filtering parameters evaluated by Washburn and co-workers [11] Accepted $X_{\text {corr }}$ values for +1 charged fully tryptic peptides were higher than 1.9 , over 2.2 or 3.3 for fully and partially tryptic +2 and +3 charged peptides. The $\Delta C_{\mathrm{n}}$ values were above 0.08 for all analyzed spectra. Basing on the results obtained for each HeLa sample type, the proteins, detected only in one of four of them, were distinguished (Table 1, Online Resources ESM_1).

\section{Functional Bioinformatic Analysis of the HeLa Differentiating Proteins}

The bioinformatic analysis of the HeLa differentiating proteins was performed with the use of PANTHER Classification System (Protein ANalysis THrough Evolutionary Relationships). The gene names of these proteins were uploaded to the PANTHER Gene List Analysis tool, freely available at [12]. The proteins were classified and organized according to their gene ontology (GO) molecular function (Fig. 1) and PANTHER protein class (Fig. 2) categories. The results were depicted in pie charts. The assigned to each category proteins were also presented on sides of the pie charts.

\section{PDI Concentration Measurement}

The verification of protein disulphide isomerase (PDI) levels in the investigated HeLa cell cultures was performed using Enzyme-linked Immunosorbent Assay (ELISA) Kit for Human Protein Disulphide Isomerase from Uscn Life Science Inc. (Wuhan, Hubei, PRC), according to the producer's instructions. The colorimetric measurements were performed on Multiskan FC Microplate Photometer (Thermo Scientific, Rockford, IL, USA) at the wavelength of $450 \mathrm{~nm}$. The assay detection range was from 0.312 to $20 \mathrm{ng} \mathrm{mL}^{-1}$. The PDI concentrations were determined then by comparing the samples O.D. to the standard curve and normalized to total protein concentration for each sample. The data were calculated as nanograms of PDI per milligram of total protein.

The obtained PDI concentrations for each type of differently stimulated HeLa cells, namely HeLaIL-1, HeLaCHX and HeLaIL-1/CHX, were then compared to the PDI 
Table 1 Differentiating proteins from the investigated HeLa proteomes, identified in the HPLC-MS/MS analysis

\begin{tabular}{|c|c|c|c|}
\hline HeLa sample & Protein name & Gene name & SwissProt Acc. \# \\
\hline \multirow[t]{15}{*}{ HeLaK } & $26 \mathrm{~S}$ protease regulatory subunit $6 \mathrm{~A}$ & PSMC3 & P17980 \\
\hline & $60 \mathrm{~S}$ ribosomal protein $\mathrm{L} 7$ & RPL7 & P18124 \\
\hline & ATPase inhibitor, mitochondrial & ATPIF1 & Q9UII2 \\
\hline & CD2-associated protein & $\mathrm{CD} 2 \mathrm{AP}$ & Q9Y5K6 \\
\hline & Collagen alpha-1(III) chain & COL3A1 & P02461 \\
\hline & Filamin-B & FLNB & O75369 \\
\hline & Fructose-bisphosphate aldolase A & ALDOA & P04075 \\
\hline & High mobility group protein B1 & HMGB1 & P09429 \\
\hline & Histone H1.3 & HIST1H1D & P16402 \\
\hline & Histone $\mathrm{H} 2 \mathrm{~B}$ type $1-\mathrm{C}$ & HIST1H2BC & P62807 \\
\hline & Kinesin family member 13A & KIF13A & Q5JV47 \\
\hline & Nesprin-2 beta 2 & SYNE2 & Q86YP9 \\
\hline & Protein SET & SET & Q01105 \\
\hline & Serum albumin & ALB & P02768 \\
\hline & Taste receptor type 2 member 60 & TAS2R60 & P59551 \\
\hline \multirow[t]{17}{*}{ HeLaCHX } & 40S ribosomal protein $\mathrm{S} 20$ & RPS20 & P60866 \\
\hline & $60 S$ ribosomal protein L21 & RPL21 & P46778 \\
\hline & 60S Ribosomal protein L5 & RPL5 & P46777 \\
\hline & A disintegrin and metalloproteinase domain-containing protein 2 & ADAM2 & Q99965 \\
\hline & Aldo-keto reductase family 1 member $\mathrm{C} 3$ & AKR1C3 & P42330 \\
\hline & Collagen alpha-2(XI) chain precursor & COL11A2 & P13942 \\
\hline & Endoplasmin & HSP90B1 & P14625 \\
\hline & Immunoglobulin superfamily member 10 & IGSF10 & Q6WRI0 \\
\hline & Metalloproteinase TIKI1 precursor & TRABD2A & Q86V40 \\
\hline & Moesin & MSN & P26038 \\
\hline & Neuroepithelial cell-transforming gene 1 protein & NET1 & Q7Z628 \\
\hline & Protein QN1 homolog & QN1 & Q5TB80 \\
\hline & Protein sprouty homolog 2 & SPRY2 & O43597 \\
\hline & RNA-binding protein MEX3B & MEX3B & Q6ZN04 \\
\hline & Small glutamine-rich tetratricopeptide repeat-containing protein alpha & SGTA & O43765 \\
\hline & Triosephosphate isomerase & TPI1 & P60174 \\
\hline & V3-3 protein & IGLV7-46 & Q5NV83 \\
\hline \multirow[t]{18}{*}{ HeLaIL-1 } & $60 \mathrm{kDa}$ heat shock protein, mitochondrial & HSPD1 & P10809 \\
\hline & $60 \mathrm{~S}$ ribosomal protein $\mathrm{L} 12$ & RPL12 & P30050 \\
\hline & Argininosuccinate synthetase 1 & ASS1 & P00966 \\
\hline & ATP-citrate synthase & ACLY & P53396 \\
\hline & Calnexin & CANX & $\mathrm{P} 27824$ \\
\hline & Chaperonin containing TCP1, subunit 3 (Gamma) & СCT3 & P49368 \\
\hline & Complement component $1 \mathrm{Q}$ subcomponent-binding protein, mitochondrial & C1QBP & Q07021 \\
\hline & DNA helicase B & HELB & Q8NG08 \\
\hline & Extracellular sulfatase Sulf-2 & SULF2 & Q8IWU5 \\
\hline & Glutathione S-transferase P & GSTP1 & P09211 \\
\hline & Heat shock protein HSP 90-alpha & HSP90AA1 & P07900 \\
\hline & Hepatoma-derived growth factor & HDGF & P51858 \\
\hline & Heterogeneous nuclear ribonucleoprotein $\mathrm{U}$ & HNRNPU & Q00839 \\
\hline & Hydroxyacyl-coenzyme A dehydrogenase, mitochondrial & HADH & Q16836 \\
\hline & Keratin, type I cytoskeletal 16 & KRT16 & $\mathrm{P} 02533$ \\
\hline & Keratin, type II cytoskeletal 7 & KRT7 & P08729 \\
\hline & Kynureninase & KYNU & Q16719 \\
\hline & La-related protein 1 & LARP1 & Q6PKG0 \\
\hline
\end{tabular}


Table 1 (continued)

\begin{tabular}{|c|c|c|c|}
\hline HeLa sample & Protein name & Gene name & SwissProt Acc. \# \\
\hline & Leucine-rich repeats and immunoglobulin-like domains protein 3 & LRIG3 & Q6UXM1 \\
\hline & Mutant desmin & DES & Q45VM7 \\
\hline & Netrin receptor DCC & $\mathrm{DCC}$ & P43146 \\
\hline & Nucleosome assembly protein 1-like 1 & NAP1L1 & P55209 \\
\hline & Olfactory receptor 9G4 & OR9G4 & Q8NGQ1 \\
\hline & Peroxiredoxin-2 & PRDX2 & P32119 \\
\hline & Phosphoglycerate kinase & PGK1 & P00558 \\
\hline & Poly(A) binding protein 1 & PABPC1 & P11940 \\
\hline & Poly(rC) binding protein 2 & PCBP2 & Q15366 \\
\hline & Potassium voltage-gated channel subfamily B member 1 & $\mathrm{KCNB} 1$ & Q14721 \\
\hline & Protein disulphide-isomerase & $\mathrm{P} 4 \mathrm{HB}$ & P07237 \\
\hline & RNA-binding protein 10 isoform 2 & RBM10 & P98175-2 \\
\hline & TATA-binding protein-associated factor 172 & BTAF1 & O14981 \\
\hline & Transcriptional activator Myb & MYB & P10242 \\
\hline & Transient receptor potential cation channel, subfamily C, member 4 & TRPC4 & Q9UBN4 \\
\hline & Uncharacterized protein C1orf 168 & C1orf168 & Q5VWT5 \\
\hline & Vinculin & VCL & P18206 \\
\hline & X-ray repair cross-complementing protein 6 & XRCC6 & P12956 \\
\hline \multirow[t]{14}{*}{ HeLaIL-1/CHX } & $40 S$ ribosomal protein $\mathrm{S} 7$ & RPS7 & P62081 \\
\hline & A disintegrin and metalloproteinase domain-containing protein 21 & ADAM21 & Q9UKJ8 \\
\hline & Chaperonin containing TCP1, subunit 2 (Beta), isoform CRA_c & $\mathrm{CCT} 2$ & P78371 \\
\hline & Chaperonin containing TCP1, subunit $6 \mathrm{~A}$ isoform a variant & CCT6A & P40227 \\
\hline & Homeodomain-interacting protein kinase 3 & HIPK3 & Q9H422 \\
\hline & L-lactate dehydrogenase A chain & LDHA & P00338 \\
\hline & LRP1 protein & LRP1 & Q7Z7K9 \\
\hline & MHC lymphocyte antigen & HLA-G & Q9TP13 \\
\hline & Non-histone chromosomal protein HMG-17 & HMGN2 & P05204 \\
\hline & Non-POU domain-containing octamer-binding protein & NONO & Q15233 \\
\hline & Presenilin-1 & PSEN1 & P49768 \\
\hline & Protein FAM9C & FAM9C & Q8IZT9 \\
\hline & Protocadherin-17 & PCDH17 & O14917 \\
\hline & Tubulin beta-4B chain & TUBB4B & P68371 \\
\hline
\end{tabular}

The details about the proteins identification can be found in the Online Resource (ESM_1)

concentration in the control sample (HeLaK). Statistical significance of the differences in PDI concentrations between these samples was verified using $t$ Student test on Statistica 10.0 software (Statsoft, Tulsa, OK, USA). The differences were considered as statistically significant, when obtained for them $p$ values were below 0.05 .

\section{Results and Discussion}

\section{Induction of the Cytocidal Effect on HeLa Cells}

The HeLa cell cultures were stimulated with IL- $1 \alpha$ (HeLaIL-1), CHX (HeLaCHX) or both IL- $1 \alpha$ and CHX (HeLaIL-1/CHX). One was left as a control (HeLaK). The experiments were done according with Doszczak et al. [3]. Similarly, to their findings, the cytotoxic effect on HeLa cells in our study was observed after 14-h simultaneous IL-1 $\alpha$ and CHX treatment.

\section{MS-Based Proteome Profiling}

The shotgun proteomic approach was employed to investigate changes on the molecular level, in response to IL- $1 \alpha$ and CHX that lead to TNF- $\alpha$ release and HeLa cells apoptosis. Tryptic digests of HeLa cell lysates were submitted to the HPLC-MS/MS analysis. The acquired MS/MS spectra were searched against protein sequence database to identify proteins in each of the samples (Online Resources ESM_1a-d). As a result of this preliminary screening, 85 


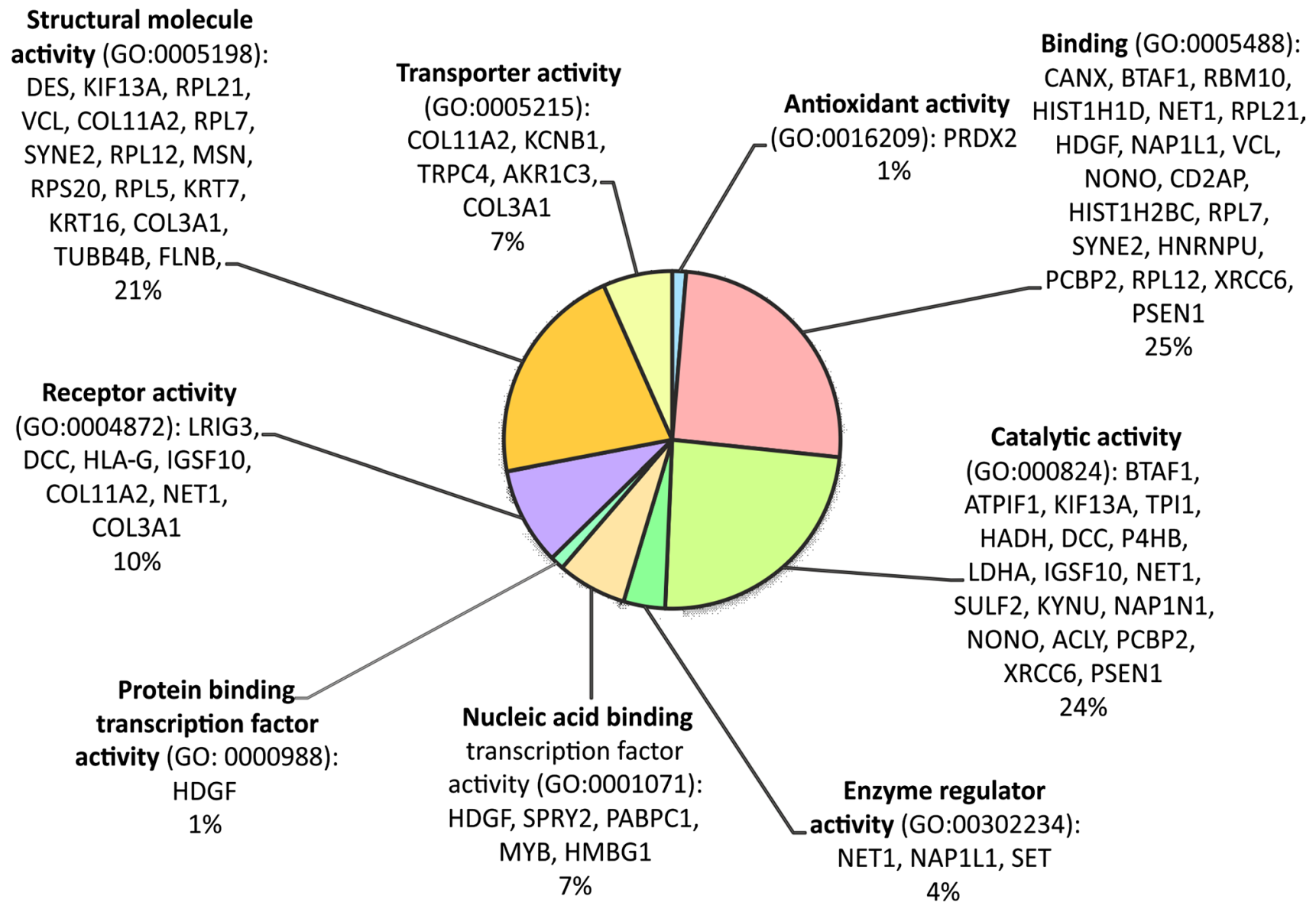

Fig. 1 Classification of the proteins, which differentiated the investigated HeLa proteomes, according to their gene ontology (GO) molecular function categories

peptides typical for 82 proteins (Online Resources ESM_2), which potentially diversified the examined proteomes, were distinguished. The comparison of the obtained proteomic profiles enabled to select proteins, which were found only in the control HeLa cells-HeLaK (15), in HeLa cells treated with IL-1 $\alpha$-HeLaIL-1 (36) or with CHX-HeLaCHX (17) and in the ones subjected to simultaneous IL-1 $\alpha$ and CHX stimulation-HeLaIL-1/CHX (14) (Table 1, Online Resources ESM_1a-d and ESM_2). These proteins may be candidates for further detailed examination in view of their role in the mechanism of endogenous TNF- $\alpha$ secretion upon the co-influence of IL- $1 \alpha$ and CHX. In the group of the proteins that differentiated the analyzed proteomes only protein disulphide isomerase (PDIA1_HUMAN) and complement component $1 \mathrm{Q}$ subcomponent-binding protein mitochondrial (C1QBP_HUMAN) were identified basing on two characteristic peptides. For other differentiating proteins, there were only single characteristic peptides detected on the applied level of confidence. Those single peptide identifications should be considered with caution and require additional validation, e.g. with ELISA test, western blot or targeted for them quantitative LC-MS/MS analysis to unambiguously determine their expression levels in the samples. The distinguished proteins represented various groups and were characterized by different functions. To get comprehensive understanding of their complex nature and explore their relationships, a bioinformatic tool-the PANTHER Classification System was employed [13]. The classification results were presented in pie charts, which represent: the molecular functions of these proteins (GO Molecular Function, Fig. 1) and the protein classes (PANTHER Protein Class, Fig. 2).

\section{Influence of Protein Disulphide Isomerase (PDI) on TNF- $\alpha$ Mediated Cell Death}

Among the proteins selectively identified in one of four investigated HeLa proteomes, a protein disulphide isomerase (PDI, SwissProt ID: PDIA1_HUMAN, SwissProt accession number: $\mathrm{P} 07237, \mathrm{EC}=5.3 .4 .1$ ) seems to be particularly interesting for future research. This multifunctional protein, localized in endoplasmic reticulum (ER), plays important biological roles by catalyzing formation, 


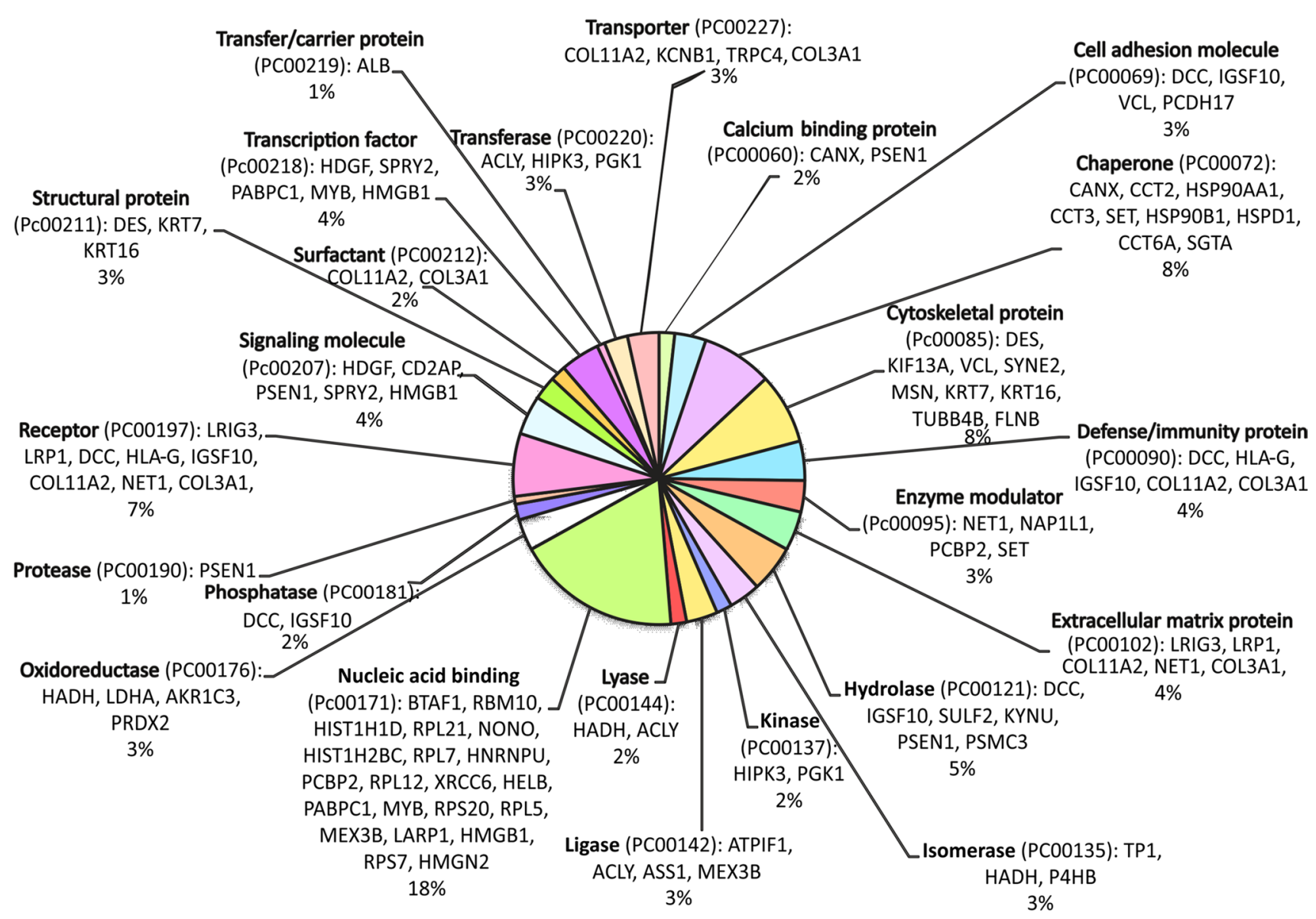

Fig. 2 Classification of the proteins, which differentiated the investigated HeLa proteomes, according to their PANTHER protein class categories

breakage and reorganization of disulphide bonds, and participating in the cell redox homeostasis [14]. The research of Zhou and co-workers [6], in which they induced sepsis in rats by application of lipopolysaccharide, revealed that PDI (P4HB) gene expression was lower, whereas the one encoding the TNF- $\alpha$ increased. In turn, TNF- $\alpha$, together with other proinflammatory cytokines (e.g. IL- $\beta$ or IL-6) is crucial in the initiation and progression of sepsis. It was also noticed that addition of bacitracin-a specific PDI inhibitor, to the RAW 264.7 mouse macrophages cell line can cause an increased expression of the gene encoding TNF- $\alpha$ in a dose-dependent manner. The conformational changes of the TNF- $\alpha$ converting enzyme- - disintegrin and metalloproteinase-17 (ADAM17) caused by PDI lead also to downregulation of ADAM17 enzymatic activity and prevent pro-TNF- $\alpha$ processing to the secreted form $[7,8]$. Moreover, inhibition of PDI was shown to prevent unfolded protein response (UPR), induced by endoplasmic reticulum stress. The UPR is an adaptive intracellular mechanism of response to protein misfolding implicated in various pathophysiological states, including cancer or neurodegenerative diseases [15]. Its inhibition led to apoptosis of A375 human melanoma cell line. Therefore, PDI was indicated as a potential target for drugs, which enhance the anticancer therapy effectiveness [16]. Interestingly, it was also evidenced that PDI contributes to the increase of viability of the leukemia cell lines (HL 60 and NB4 AML) treated with daunorubicin-a cytostatic anthracycline used in cancers therapies. Instead, their additional treatment with cycloheximide caused cell death [17]. PDI belongs to the proteins that occur in rather high amounts in cells. Therefore, lack of its detection in our HPLC-MS/MS experiment in other analyzed cell lines, especially in the control HeLaK, might be an effect of the presence of other, more abundant proteins, which had, therefore, more chances to reach the MS detector during the analysis. In turn, the fact of its identification in HeLa cells stimulated with IL-1 $\alpha$ (Table 1 ), in which cytotoxic effect was not observed, may indicate that cellular stress induced by this cytokine causes UPR activation and increases PDI synthesis. However, in the condition of supplemental protein synthesis inhibition by CHX (HeLaIL-1/ 
$\mathrm{CHX}$ ), in which an apoptotic process was intensive, this repairing mechanism could be disturbed, hence more probable lack of PDI detection.

\section{Protein Disulphide Isomerase is Up-regulated in HeLa Cells Stimulated Only with IL-1 $\alpha$}

To verify quantitative relationships between PDI levels in the control HeLa cells (HeLaK) and the cells upon stimuli with IL-1 $\alpha$ (HeLaIL-1), cycloheximide (HeLaCHX) or both of these agents (HeLaIL-1/CHX), the ELISA test was performed. The PDI concentrations in the cellular supernatants, obtained after cell lysis, were determined using a human specific ELISA and titrations of human PDI as the standard to calibrate the system. As expected, PDI could be detected in all investigated cells, but in varied levels. The average PDI concentrations were: $42.67( \pm 27.22) \mathrm{ng} \mathrm{mg}^{-1}$ of total protein for control HeLaK, $79.20( \pm 7.50) \mathrm{ng} \mathrm{mg}^{-1}$ of total protein for HeLaIL-1, $55.31( \pm 21.50) \mathrm{ng} \mathrm{mg}^{-1}$ of total protein for HeLaCHX and $50.55( \pm 18.52) \mathrm{ng} \mathrm{mg}^{-1}$ of total protein for HeLaIL-1 $\alpha / \mathrm{CHX}$. Increased levels of PDI protein were present in the detergent soluble fractions of HeLa cells treated with IL-1 $\alpha$. The statistical analysis of the results proved that the PDI level in HeLaIL-1 was significantly higher than the level of this protein in the non-stimulated cells $(p=0.046$ and $t=2.632$ ). Furthermore, it was also higher than the PDI concentration in the HeLaIL-1/CHX cells $(p=0.035$ and $t=2.869$ ). In contrast, comparing to the control, the PDI levels were not significantly enhanced in the detergent soluble fractions of HeLa cells treated alone with CHX ( $p=0.546$ and $t=0.662$ ) or simultaneously with IL- $1 \alpha$ and CHX ( $p=0.699$ and $t=0.415)$. On the level of significance $p=0.05$, also the PDI levels between HeLaCHX and HeLa IL-1 ( $p=0.083$ and $t=2.078)$ did not varied significantly. These data suggest that the up-regulation of PDI in the HeLa cells exposed to IL- $1 \alpha$ may contribute to the protection against apoptosis. Next, in case of the IL- $1 \alpha$ and CHX-treated cells, where the increase of the PDI concentration was not significant, the stress caused the release of cytotoxic TNF- $\alpha$.

\section{Characterization of PDI in Relation with Other Proteins Differentiating the Investigated HeLa Proteomes: Potential Implication of Unfolded

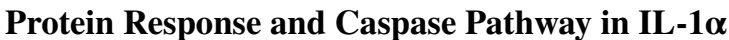 and CHX-induced Cytotoxicity}

PDI, together with other cooperating proteins, may prevent cell death mediated by TNF- $\alpha$. One of them may be calnexin (CALX) detected in the presented experiment in HeLaIL-1 cells (Table 1, Online Resources ESM_1). CALX retains unfolded glycoprotein intermediates through oligosaccharide moieties, until they fold correctly, or are being degraded
[18]. Except PDI, nascent proteins synthesized in ER interact with other folding enzymes. These ER chaperones are also capable of compensating the lack of some of their representatives by up-regulating of the others [19]. The hypothesis of the ER stress pathway contribution to the mechanism of IL- $1 \alpha$ and CHX-triggered cytocidal effect on HeLa cells, may be supported by the endoplasmin (HSP90B1) occurrence in the HeLaCHX. It is also a member of the ER protein folding control machinery and a hallmark of UPR. The protein is also an obligate chaperone for insulin growth factor (IGF), thereby participating in the IGF-driven UPR potentiating and mediated by it anti-apoptotic signalling [20]. Therefore, HSP90B1 identification in the HeLaCHX cells (Table 1) may suggest that in these cells the ER stress response mechanism was still active. Thereby, the cytotoxic effect was visible in the cells treated with CHX, although in a lower degree than in HeLaIL-1/CHX cells.

In HeLa cells, exposed to IL- $1 \alpha$ and CHX, two other interesting proteins were detected: presenilin 1 (PSEN1) and protocadherin 17 (PCDH17) (Table 1). PCDH17 acts as a tumor suppressor. The protein causes anti-proliferative activity through induction of both, apoptosis and autophagy. Similarly, to several other members of cadherin superfamily (e.g., cadherins $\mathrm{CDH} 1$ and $\mathrm{CDH} 11$, protocadherins PCDH8 and PCDH10), functional inactivation or expression loss of this protein has been shown in various cancer types, such as gastric and colorectal cancer [21], resulting in tumor cell invasion and metastasis. The silencing of PCDH17 expression was observed in case of oesophageal squamous cell carcinoma (ESCC) [22] as well. Conversely, in normal oesophageal tissues and other tissues with squamous epithelial cells, such as cervix or skin, PCDH17 expression was present or higher than in cancerous ones. Results of these experiments suggested that PCDH17 contributes to the arrest of ESCC cells at the $\mathrm{G}_{1}-\mathrm{S}$ checkpoint. The PSEN1 is also involved in the control of $\mathrm{G}_{1}$ to $\mathrm{S}$ cell cycle phase transition. The loss of this negative regulator of $\beta$-catenin signalling, and the resulting further cyclin D1 transcriptional activity, was shown to lead to the epidermal hyperplasia and skin tumors development in adult mice [23]. Therefore, detection of PCDH17 and PSEN1 in the HeLaIL-1/CHX cells may suggest their lower proliferative activity, which is more characteristic to normal, non-cancerous cells. The two other proteins found exclusively in the HeLa cells treated simultaneously with IL- $1 \alpha$ and CHX-MHC lymphocyte antigen (HLA-G) and tubulin beta-4B chain (TUBB4B) may be considered as hallmarks of the TNF- $\alpha$ cytotoxic activity. This may be supported by the fact that TUBB4B is one of the most abundant $\beta$-tubulin isotype in many tumors [24]. It is also worth noting that Abd-El-Basset and co-workers in the research on microglia [25] proved that the amount of total tubulin increases after treatment with TNF- $\alpha$ and IL- $1 \beta$. Therefore, in our case, the detection of TUBB4B in the HeLaIL-1/CHX, but 
not in other studied HeLa proteomes, seems to be dependent on the increased expression of this protein, as a result of the IL- $1 \alpha$ stimulation and TNF- $\alpha$ activity. In turn, HLA-G is known to play a role in cancer immunoediting process. The aberrant expression of this molecule by tumor cells has been suggested to be implicated in the strategies that they use to escape from the host immunosurveillance [26]. It was also shown, however, that soluble HLA-G stimulates the release of TNF- $\alpha$ to the culture media of peripheral blood mononuclear cells (PMBCs) incubated with membrane HLA-G expressing cells and soluble HLA-G [27]. What is more, Chen et al. [28] proved that up-regulated soluble HLA-G (sHLA-G) expression on PMBCs in ankylosing spondylitis correlates with acute phase reactants and decreases after the TNF- $\alpha$ blocker therapy. On the other hand, the HLA-G molecule might be also considered as a factor participating in the IL- $1 \alpha$ and CHX-elicited, and mediated by the release of TNF- $\alpha$ the HeLa cells cytotoxicity. Fons et al. proved that soluble HLA-G induces endothelial cells apoptosis, which implicates caspase pathway. In their experiments, the incubation of HUVEC cells with recombinant sHLA-G1 induced these endothelial cells apoptosis, while the addition of broad-spectrum caspase inhibitor, zVAD-fmk, blocked this effect [29]. The possible implication of caspase pathway in IL-1 $\alpha$-induced HeLa cells killing is consistent with the previous experiments [3]. They confirmed that cells death caused by both, IL- $1 \alpha$ and TNF- $\alpha$, can be antagonized by the above-mentioned zVAD-fmk inhibition of caspases. In conditions, in which protein misfolding can no longer be compensated, the extended UPR elicits apoptosis just by the caspase pathway [30]. This could explain, in our experiment, the presence of the endoplasmic reticulum stress response proteins, as well as the ones involved in mediated by caspases cascade programmed cell death.

\section{Conclusions}

The applied HPLC-MS/MS qualitative proteomic approach enabled to find candidates for further investigation on the nature of the mechanism of enhanced biological cytotoxic activity of TNF- $\alpha$ on HeLa cells after exposure to IL- $1 \alpha$ and CHX. Among potentially differentiating proteins, a protein disulphide isomerase expression was validated using ELISA test. Presence of the other differentiating proteins, especially in case of single peptide identifications, should be considered with caution and remains to be validated, e.g., using ELISA, western blot or targeted LC-MS/MS approach, in future experiments. The proteins identified in this study suggest that the unfolded protein response mechanism together with caspase pathway may be involved in this process. Determined by the ELISA test, up-regulation of protein disulphide isomerase (PDI) indicates that this protein may be implicated in the mechanism, which protected the HeLa cells exposed to IL- $1 \alpha$ against TNF- $\alpha$ release. It was disturbed, when the HeLa cells were stimulated additionally with cycloheximide. The PDI levels in HeLaIL-1/CHX cells did not increase significantly and the TNF- $\alpha$ secretion led to their apoptosis. Further work could also help to elucidate more precisely the quantitative relations between PDI and other proteins cooperating in this process.

Acknowledgements The research leading to these results has received funding from the European Union Seventh Framework Programme FP7/2007-2013 under Grant Agreement no. 316094. The scientific work was financed from funds for science in the years 2013 2016 allocated for the internationally co-financed project. The authors would also like to thank Dr. Aleksandra Dyś (Department of Laboratory Medicine MUG), for her valuable remarks.

\section{Compliance with ethical standards}

Conflict of interest The authors declare that they have no conflict of interest.

Ethical statement The research described in this publication does not contain any studies with human participants or animals performed by any of the authors.

Open Access This article is distributed under the terms of the Creative Commons Attribution 4.0 International License (http://creativecommons.org/licenses/by/4.0/), which permits unrestricted use, distribution, and reproduction in any medium, provided you give appropriate credit to the original author(s) and the source, provide a link to the Creative Commons license, and indicate if changes were made.

\section{References}

1. Morgan MJ, Liu Z (2010) Reactive oxygen species in TNF $\alpha$ induced signaling and cell death. Mol Cells 30:1-12

2. Lachman LB, Dinarello CA, Llansa ND, Fidler IJ (1986) Natural and recombinant human interleukin $1 \beta$ is cytotoxic for human melanoma cells. J Immunol 136:3098-3102

3. Doszczak M, Pierzchalski A, Grzenkowicz J, Stasiłojć G, Bigda JJ (2008) Cytocidal effect of interleukin-1 (IL-1) on HeLa cells is mediated by both soluble and transmembrane tumor necrosis factor (TNF). Cytokine 42(2):243-255

4. Bensimon A, Heck AJR, Aebersold R (2012) Mass spectrometry-based proteomics and network biology. Annu Rev Biochem 81:379-405

5. Yates JR, Ruse CI, Nakorchevsky A (2009) Proteomics by mass spectrometry: approaches, advances and applications. Annu Rev Biomed Eng 11:49-79

6. Zhou M, Jacob A, Miksa MR, Wu Maitra SR, Wang P (2008) Downregulation of protein disulphide isomerase in sepsis and its role in tumor necrosis factor-alpha release. Crit Care 12:R100

7. Willems SH, Tape CJ, Stanley PL, Taylor NA, Mills IG, Neal DE, McCafferty J, Murphy G (2010) Thiol isomerase negatively regulate the cellular shedding activity of ADAM 17. Biochem J 428:439-450

8. Düsterhöft S, Jung S, Hung C-W, Tholey A, Sönnichsen FD, Grötzinger J, Lorentzen I (2013) Membrane-proximal domain of a disintegrin and metalloproteinase-17 represents the putative 
molecular switch of its shedding activity operated by protein disulphide isomerase. J Am Chem Soc 135(15):5776-5781

9. Borenfreund E, Puerner J (1985) Toxicity determined in vitro by morphological alterations and neutral red absorption. Toxicol Lett 24:119-124

10. UniProtKB (2013) http://www.uniprot.org/uniprot/. Accessed 13 Dec 2013

11. Washburn MP, Wolters D, Yates JR III (2001) Large-scale analysis of the yeast proteome by multidimensional protein identification technology. Nat Biotechnol 19:242-247

12. PANTHER Classification System (2013) http://www.pantherdb. org/. Accessed 15 Dec 2013

13. Mi H, Muruganujan A, Thomas PD (2013) PANTHER in 2013: modelling the evolution of gene function, and other gene attributes, in the context of phylogenetic trees. Nucl Acids Res 41(Database issue):D377-D386

14. Appenzeller-Herzog C (2011) Glutathione- and non-glutathionebased oxidant control in the endoplasmic reticulum. J Cell Sci 124:847-855

15. Wang S, Kaufman RJ (2012) The impact of the unfolded protein response in human disease. J Cell Biol 197(7):857-867

16. Lovat PE, Corazzari M, Armstrong JL, Martin S, Pagliarini V, Hill D, Brown AM, Piacentini M, Birch-Machin MA, Redfern CPF (2008) Increasing melanoma cell death using inhibitors of protein disulphide isomerases to abrogate survival responses to endoplasmic reticulum stress. Cancer Res 68:5363-5369

17. Gausdal G, Gjersten BT, McCormack E, Van Damme P, Hovland R, Krakstad C, Bruserud Ø, Gevaert K, Vandekerckhove J, Døskeland SO (2008) Abolition of stress-induced protein synthesis sensitizes leukemia cells to anthracycline-induced death. Blood 111:2866-2877

18. Morito D, Nagata K (2012) ER stress proteins in autoimmune and inflammatory diseases. Front Immun 3:48

19. Prell T, Lautenschläger J, Grosskreutz J (2013) Calcium-dependent protein folding in amyotrophic lateral sclerosis. Cell Calcium 54:132-143

20. Marzec M, Eletto D, Argon Y (2012) GRP94: an HSP90-like protein specialized for protein folding and quality control in the endoplasmic reticulum. Biochim Biophys Acta 1823:774-787

21. Hu X, Sui X, Li L, Huang X, Rong R, Su S, Shi Q, Mo L, Shu X, Kuang Y, Tao Q, He C (2013) Protocadherin 17 acts as tumor suppressor inducing tumor cell apoptosis and autophagy, and is frequently methylated in gastric and colorectal cancers. J Pathol 229:62-73

22. Haruki S, Imoto I, Kozaki K, Matsui T, Kawachi H, Komatsu S, Muramatsu T, Shimada Y, Kawano T, Inazawa J (2010) Frequent silencing of protocadherin 17, a candidate tumor suppressor for esophageal squamous cell carcinoma. Carcinogenesis 31(6): 1027-1036

23. Xia X, Qian S, Soriano S, Wu Y, Fletcher AM, Wang XJ, Koo $\mathrm{EH}, \mathrm{Wu}$ X, Zheng H (2001) Loss of presenilin 1 is associated with enhanced $\beta$-catenin signaling and skin tumorigenesis. Proc Natl Acad Sci USA 98(19):10863-10868

24. Leandro-García J-L, Leskelä S, Landa I, Montero-Conde C, López-Jiménez E, Letón R, Cascón A, Robledo M, RodríguezAntona C (2010) Tumoral and tissue specific expression of the major human $\beta$-tubulin isotypes. Cytoskeleton 67:214-223

25. Abd-El-Basset EM, Prashanth J, Ananth Lakshmi KVV (2004) Up-regulation of cytoskeletal proteins in activated microglia. Med Princ Pract 13:325-333

26. Carosella ED, Horuzsko A (2007) Editorial: HLA-G in cancer. Sem Cancer Biol 17:411-412

27. Kanai T, Fujii T, Kozuma S, Yamashita T, Miki A, Kikuchi A, Taketani Y (2001) Soluble HLA G influences the release of cytokines from allogeneic peripheral blood mononuclear cells in culture. Mol Hum Reprod 7(2):195-200

28. Chen C-H, Liao H-T, Chen H-A, Liu C-H, Liang T-H, Wang C-T, Tsai C-Y, Chou C-T (2010) Human leukocyte antigen-G in aknylosing spondylitis and the response after tumor necrosis factor- $\alpha$ blocker therapy. Rheumatology 49:264-270

29. Fons P, Chabot S, Cartwright JE, Lenfant F, L'Faquihi F, Guistiniani J, Herault J-P, Gueguen G, Bono F, Savi P, Aguerre-Girr M, Fournel S, Malecaze F, Bensussan A, Plouët J, Le Bouteiller P (2006) Soluble HLA-G1 inhibits angiogenesis through an apoptotic pathway and by direct binding to CD160 receptor expressed by endothelial cells. Blood 108:2608-2615

30. Morishima N, Nakanishi K, Takenouchi H, Shibata T, Yasuhiko Y (2002) An endoplasmic reticulum stress-specific caspase cascade in apoptosis. J Biol Chem 277(37):34287-34294 